\title{
Quantitative Job Insecurity and Well-Being: Testing the Mediating Role of Hindrance and Challenge Appraisals
}

\section{Morteza Charkhabi* \\ Department of Psychology, National Research University Higher School of Economics, Moscow, Russia}

OPEN ACCESS

Edited by:

Gabriela Topa,

Universidad Nacional de Educación

a Distancia (UNED), Spain

Reviewed by:

Rajneesh Choubisa,

Birla Institute of Technology

and Science, India

Paula Benevene,

Libera Università Maria SS. Assunta,

Italy

${ }^{*}$ Correspondence:

Morteza Charkhabi

mcharkhabi@hse.ru

Specialty section:

This article was submitted to

Organizational Psychology,

a section of the journal

Frontiers in Psychology

Received: 10 September 2018

Accepted: 24 December 2018

Published: 25 January 2019

Citation:

Charkhabi M (2019) Quantitative Job Insecurity and Well-Being: Testing the Mediating Role of Hindrance and

Challenge Appraisals.

Front. Psychol. 9:2776.

doi: 10.3389/fpsyg.2018.02776
The aim of this study is to determine the extent to which cognitive appraisals of job insecurity may mediate the link between job insecurity and well-being among employees. According to cognitive appraisal theory, the two cognitive appraisals of job insecurity, hindrance vs. challenge appraisals, were integrated into a conceptual model and examined as the mediators of job insecurity-wellbeing association. Wellbeing related outcomes were job satisfaction and emotional exhaustion. Hypotheses were tested using a total sample of 306 hospital staff ${ }^{1}$. Respondents from diverse departments of this hospital were recruited and completed scales on quantitative job insecurity, hindrance vs. challenge appraisals of job insecurity, job satisfaction, and emotional exhaustion. Results indicated that hindrance appraisals of job insecurity mediated the association between job insecurity and emotional exhaustion. Challenge appraisals did not mediate the job insecurity-well-being association. In all, only one out of four mediation paths was found significant. As a result, employees hindered by job insecurity are more likely to be emotionally exhausted.

Keywords: job insecurity, well-being, hindrance appraisals, challenge appraisals, job satisfaction, emotional exhaustion

\section{INTRODUCTION}

Job insecurity, as a worldwide chronic work stressor, has attracted increased research attention since the beginning of the 21st century (i.e., McDonough, 2000; Probst, 2008; De Witte et al., 2015). Many studies have explored the detrimental effects of this stressor on employees and organizations (i.e., De Witte, 2005; Jiang and Probst, 2015). Job insecurity is mainly defined as an overall concern of an employee about the continued existence of the job in the future (Vander Elst et al., 2010b). Recent studies show that the current economic climate, instability in employment conditions, and largescale structural changes may initiate or intensify the perception of job insecurity among employees (De Witte et al., 2015; Schaufeli, 2016).

Job insecurity is a two-dimensional construct that is classically divided into quantitative and qualitative job insecurity. Quantitative job insecurity is related to the concern of employees about the continued existence of their job in the future (Vander Elst et al., 2010b), while qualitative job

\footnotetext{
${ }^{1}$ The author would like to thank Mr. Ehsan Rahimi, master degree in psychology, who collected data from Iran.
} 
insecurity is related to the concern of employees about the extent to which their job features may unfavorably change (e.g., Hellgren et al., 1999; De Witte, 2005). Although studies show that both types of job insecurity can lead to negative outcomes, the focus of this study will be on quantitative job insecurity. Studies show that an increase in job insecurity is associated with an increase in various work-related strains. At the individual level, job insecurity is related to negative outcomes such as psychological distress and emotional exhaustion (e.g., Cheng and Chan, 2008; Piccoli and De Witte, 2015). At the organizational level, job insecurity is associated with a lower job satisfaction and job commitment and a higher turnover intention (Furåker and Berglund, 2013; Lim et al., 2014; Hamad et al., 2015; Wang et al., 2015). Although studying the link between job insecurity and different outcomes has gained a lot of research attention, there has been lesser attention to the underlying mechanisms that can explain this link. The current study intends to expand knowledge on the theoretical explanations of the link between job insecurity and well-being related outcomes through testing the role cognitive appraisals as the mediators.

The focus of this article is on two possible cognitive mediators, hindrance and challenge appraisals, which have the potential to mediate the detrimental effects of job insecurity on the outcomes. Consistent with previous studies (e.g., Sverke et al., 2002; Zheng et al., 2014; Öztürk et al., 2017), job satisfaction and emotional exhaustion were used as the two popular wellbeing related outcomes of job insecurity. Job satisfaction is defined as the degree to which employees have a positive affective orientation toward employment by the organization (Price, 1997). Emotional exhaustion is a chronic state of physical and emotional depletion that results from excessive job, personal demands, and/or continuous stress (Maslach and Leiter, 2008; Piccoli and De Witte, 2015).

\section{Contributions of the Current Study}

Studies show that job insecurity is a subjective construct which may vary from an individual to another (Sverke et al., 2002; De Witte, 2005). It has been found that personality and attitudinal factors can influence the link between job insecurity and wellbeing related outcomes (i.e., Vander Elst et al., 2014b; Piccoli and De Witte, 2015) but no study thus far considered the extent to which the employees' cognitive appraisals of job insecurity may affect this association. Based on appraisal theory (Lazarus and Folkman, 1984), we distinguish two types of appraisals, hindrance vs. challenge appraisals, as two cognitive mediators which may potentially explain the job insecuritywell-being association. Hindrance appraisals are related to the appraisal of threats as "harms or losses" that have not yet taken place but are anticipated to occur. Challenge appraisals are associated with the appraisal of threats as "gains or growths" in a situation and are recognized as the facilitator of personal growth and goal attainment at the individual level (Barsky et al., 2011). Empirically testing the mediating role of these two appraisals in the job insecurity-well-being association is the main aim of this study. Appraisal theory (Lazarus and Folkman, 1984) will be used as main theory and conservation of resources theory (Hobfoll, 1989) as a supplementary theory to make predictions regarding the mediating role of both appraisals.

\section{Hindrance vs. Challenge Appraisals: Mediators?}

Many current researchers (e.g., Sverke et al., 2002; Probst et al., 2013; De Witte et al., 2015, 2016) have shared the job insecurity-strain view to explain the way that job insecurity affect well-being related outcomes. Although this view has widely been corroborated (e.g., De Witte, 2005; Cheng and Chan, 2008; Schaufeli, 2016), still not much is known about the role of cognitive appraisals of job insecurity in this link. Actual job insecurity and appraisal of job insecurity are two distinct constructs. As defined, job insecurity is the concern of employees about the continued existence of the job in the future and it is considered a chronic work stressor (i.e., De Witte et al., 2015). The appraisal of an employee of job insecurity can be negative (threatening) or positive (challenging). According to appraisal theory (Lazarus and Folkman, 1984), characteristics of a situation and personal resources of an individual result in primary and secondary appraisals of a stressor/event. Primary appraisal is thought to determine if an event or aspect of the environment is perceived as a hindrance or a challenge, and is known as one of the main psychological mechanisms linking stressors to strains (Webster et al., 2011). An individual with hindrance appraisals is expected to focus on the negative aspects of a stressor (i.e., harms or losses) by overestimating negative aspects and an individual with challenge appraisals is assumed to concentrate on the positive aspects of a stressor (e.g., gains or growths) by overestimating positive aspects. Secondary appraisals involve evaluating one's capacity to cope/deal with a situation. This concerns evaluations of factors such as the personal resources of individuals to regulate a stressful situation/event (Weiss et al., 1999; Barsky et al., 2011; Vander Elst et al., 2014a). The implication of this categorization (hindrance vs. challenge) is that different individuals can interpret the same stressor in both ways (Hobfoll, 1989) and that one person can even appraise a stressor as a hindrance and challenge simultaneously (Lazarus and Folkman, 1984). For example, studies show that workload, as a popular work-related stressor, can be appraised as a challenge (e.g., Marsh, 2001) or a hindrance (e.g., Cavanaugh et al., 2000). However, this distinction still seems to be unclear for job insecurity, since the criteria of studies for considering job insecurity as a hindrance (i.e., De Witte et al., 2016) or challenge (i.e., Glavin and Schieman, 2014) has been based on its association with the outcomes of job insecurity rather than on the appraisal of job insecurity itself. Since scholars thus far have not been analyzing whether job insecurity as such (regardless of its relationship with outcomes) is appraised as a challenge or a hindrance, this research intends to fill this research gap by the direct measurement of hindrance and challenge appraisals of job insecurity. Furthermore, no study could be found to show how cognitive appraisals of job insecurity influence the association between job insecurity and well-being. As noted earlier, a hindrance appraisal of job insecurity may frustrate or pose a threat in reaching one's goals (obstacles that could be 
Total effect

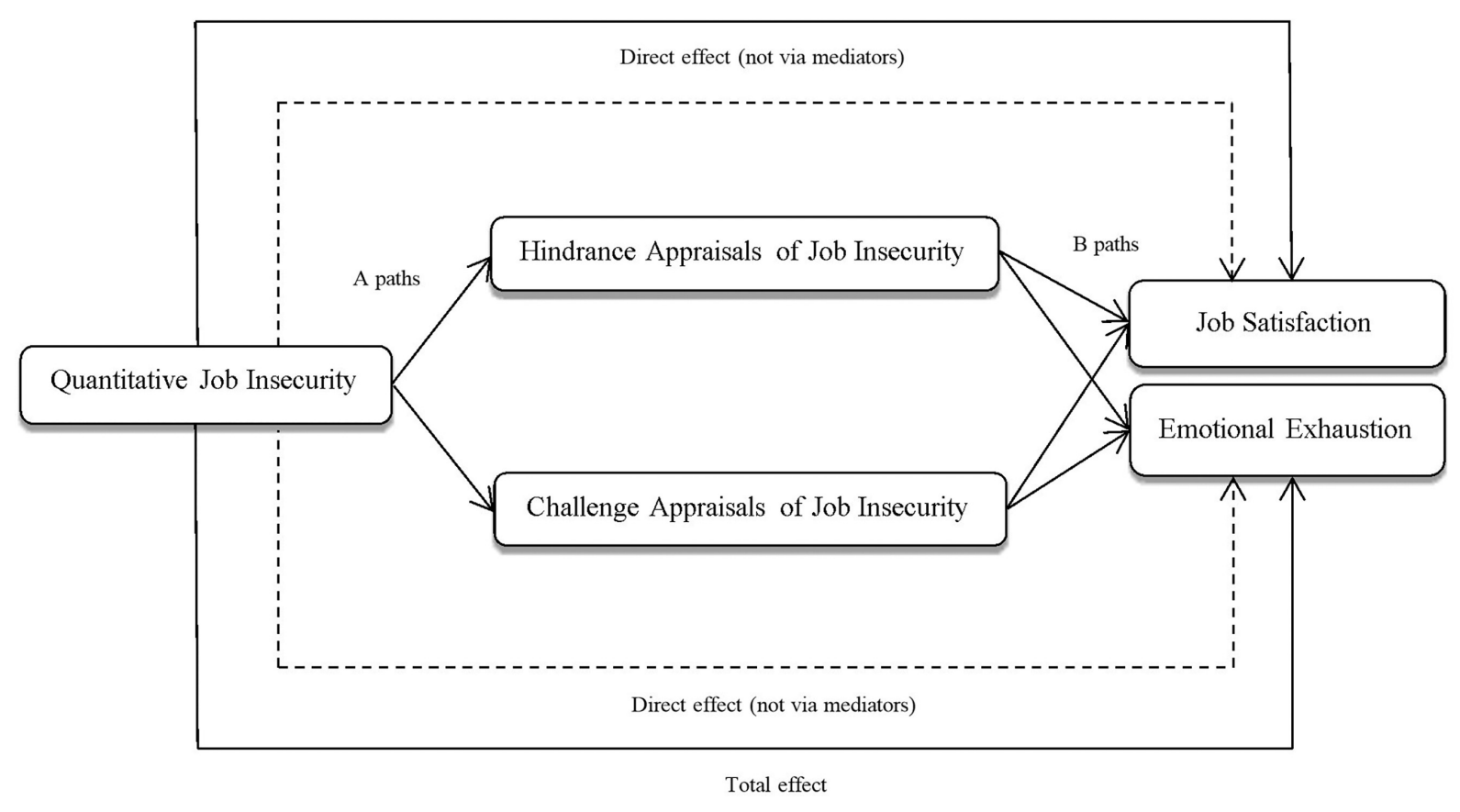

FIGURE 1 | A proposed model of the direct and in direct paths.

hardly overcome). A challenge appraisal, on the contrary, may facilitate goal achievement for individuals through being hard working to secure their job (obstacles that you think you can easily overcome) (Webster et al., 2011). By definition, hindrance appraisals may constrain or interfere with a person's perceived ability to fulfill a job demand or deal with a work stressor. On the other hand, challenge appraisals might be positively related to a person's perceived ability to fulfill a job demand or deal with a situational stressor such as job insecurity. As such, this study aims to fill this research gap by examining the mediating role of hindrance and challenge appraisals of job insecurity. This leads to the following hypotheses:

Hypothesis 1. Hindrance appraisals of job insecurity mediate the association between: (a) job insecurity and job satisfaction, and (b) job insecurity and emotional exhaustion.

Hypothesis 2. Challenge appraisals of job insecurity mediate the association between: (a) job insecurity and job satisfaction; (b) job insecurity and emotional exhaustion.

Figure 1 displays the proposed model of the relationship between the research variables. In this study, hypotheses are tested using two separate mediation paths.

\section{MATERIALS AND METHODS}

\section{Participants}

In order to test our hypotheses, surveys were administered to 368 employees from Iran. These employees were sampled from a large public hospital located in Iran. In this sample, the response rate was approximately $83 \%(N=306)$. Participants included $58.82 \%$ female and $41.18 \%$ male employees from different departments of this hospital. The mean age of the participants was 33.5 years $(S D=7.83)$, and their mean work experience was 9.4 years $(S D=7.95) .86 .6 \%$ of the participants were administrative employees (e.g., secretary, IT operator, shift planners, supervisors) and $13.4 \%$ were professional employees (e.g., nurses, medical assistants, and patient transferor, laboratory pathologist, radiologist). $20.3 \%$ had a permanent contract whereas $79.7 \%$ had a temporary contract. Finally, $88.57 \%$ of respondents had received at least a college diploma, while $11.43 \%$ had a high school diploma or less.

\section{Procedure}

The research staff distributed informed consent letters aligned with surveys among participants explaining the anonymous nature of the data collection and their rights as research participants to participate/withdraw. The participants provided written and informed consent during their working hours. To ensure that participants were comfortable to respond to the questions, they were informed that only members of the research team would have access to the data. Supervisors were not present when the data were collected.

\section{Measures}

\section{Job Insecurity}

Perceived job insecurity was measured by the four-item job insecurity scale (JIS) developed by De Witte (2000) and validated by Vander Elst et al. (2014a). This scale is a global job 
insecurity measure that corresponds to our conceptualization of job insecurity: it includes items that refer to the threat or the possibility of losing a job, as well as an item that refers to the worries associated with job loss. An example item is "I think $I$ might lose my job in the near future." Respondents were asked to rate the items on a scale from 1 (totally disagree) to 5 (totally agree). Responses were scored such that higher numbers reflect higher job insecurity. The reliability (Cronbach alpha) was 0.77 .

\section{Emotional Exhaustion}

The Maslach Burnout Inventory-General Survey (MBI-GS) (Maslach et al., 1996) was used to measure emotional exhaustion. The MBI-GS has three sub-scales; however, only the five items of the emotional exhaustion subscale was used. An example item is "I feel used up at the end of the workday." Items are scored on a 5-point frequency rating scale ranging from " 1 " (never) to "5" (daily). High scores reflect higher emotional exhaustion. The reliability (Cronbach alpha) was 0.92 .

\section{Job Satisfaction}

The four-item scale of job satisfaction developed by Price (1997) was used. An example of an item is "Most days I am enthusiastic about my job." Respondents were asked to rate the items on a five-point Likert scale from 1 (totally disagree) to 5 (totally agree). Responses were scored such that higher numbers reflect higher job satisfaction. The reliability (Cronbach alpha) was 0.72 .

\section{Hindrance vs. Challenge Appraisals of Job Insecurity}

These appraisals were measured with a scale initially constructed in Belgium (Peeters, 2014) and its latestet version developed by Charkhabi et al. (2015) in Iran and Italy. This scale included six items, three for hindrance appraisals and three for challenge appraisals. An example of an item of the challenge appraisal component is "Job insecurity makes me focus on my work so that I can perform well." An item example of the hindrance appraisal component is "Job insecurity undermines my concentration on my job." Respondents were asked to rate the items on a scale from 1 (totally disagree) to 5 (totally agree). Responses were scored such that higher scores reflect a higher hindrance or challenge appraisal. The reliability (Cronbach alpha) of the hindrance and challenge components for the Iranian sample were 0.83 and 0.70 respectively.

\section{Data Analyses}

Confirmatory factor analysis (CFA) was used to test the factorial structure of the hindrance vs. challenge appraisals of job insecurity scale using AMOS-21 (Arbuckle, 2005). The CFA was run using the maximum-likelihood method. Because a fit index reflects only a specific aspect of the model fit, a single good value cannot provide enough evidence for a good fit (Kline, 1998; Hu and Bentler, 1999; Vander Elst et al., 2010a). Thus, the goodnessof-fit of the models was estimated by means of several indexes that were interpreted relatively to each other (as suggested by Bollen and Long, 1993; Byrne, 2001): Chi-square statistic ( $\chi 2)$; Comparative fit index (CFI); Tucker-Lewis Index (TLI); Root mean square error of approximation (RMSEA); Standardized
Root Mean Square Residual (SRMR); Bayesian Information Criterion (BIC); Akaike's Information Criterion, single sample cross-validation index (AIC); and (6) Expected Cross-Validation Index (ECVI). For the RMSEA, values smaller than 0.08 indicate good fit (Browne and Cudeck, 1993; Hu and Bentler, 1999; Byrne, 2001). Values greater or equal to 0.90 on the CFI and the TLI indicate good fit (Hoyle, 1995). BIC, AIC, and ECVI are used in comparing models: the model with the smallest value of BIC, AIC, or ECVI should be chosen as the best. Since the Chi-squared statistic is sensitive to the sample size and tests whether the model shows an exact fit to the data, a finding that is rare, it should not be used as a direct indication for the goodness-of-fit of a model (Weston and Gore, 2006). Hence, it was only used to compare competing models (Weston and Gore, 2006).

\section{RESULTS}

\section{Preliminary Analyses on the "Cognitive Appraisals of Job Insecurity Scale"}

Before testing the hypotheses, the factorial structure of the hindrance vs. challenge appraisals of JIS was tested. Four models were tested and compared on the total sample size $(N=306)$ using CFA (see Table 1). At first, the model with seven items loading on one factor (cognitive appraisal) was estimated (Model 1). This model showed bad fit indexes (RMSEA $=0.26$, $\mathrm{CFI}=0.55$, TLI $=0.10$ ) and some very low factor loading (i.e., 0.35 ). To enhance the model indexes, the first model was revised and substituted with the expected two-dimensional model in which hindrance and challenge appraisals were set as the two correlated latent variables (Model 2). In Model 2, the first factor (challenge appraisal) contained four observed variables and the second factor (hindrance appraisal) three items. Model 2 showed an improvement in all fit indexes (RMSEA $=0.09, \mathrm{CFI}=0.94$, $\mathrm{TLI}=0.88)$, but one factor loading $(\mathrm{CH} 1)$ remained problematic (i.e., 0.34) and was discarded. Therefore, the third model (Model 3 ) was composed of 6 items and two covariating latent factors (see Figure 2). Fit indexes were very good (RMSEA $=0.05, \mathrm{CFI}=0.98$, TLI $=0.96$ ), and standardized factor loadings ranged from 0.69 to 0.81 and were all significantly different from zero. The covariance between the two latent factors was not significant $(r=-0.08$, $p=0.065$ ). Model 4 is a model in which the two latent factors did not covariate. The fit indexes were similar to the ones of Model 3 (RMSEA $=0.05, \mathrm{CFI}=0.98$, TLI $=0.96$ ). The very similar fit indexes of the two models show that the two models are practically identical and the two dimensions of the appraisal of job insecurity seem not to be necessarily related. However, based on the parsimony principle, the Model 3 was selected as the final model to use for further analyses. We did not need to covariate errors in the final model. The final model, with standardized factor loadings, is illustrated in Figure 2.

\section{Descriptive Statistics}

The descriptive statistics of the scales (means and standard deviations) and the Pearson correlations between the variables are reported in Table 2. In the total sample $(N=306)$, the correlation matrix indicated that job insecurity is negatively 
TABLE 1 | Goodness-of-Fit indexes of challenge-hindrance appraisal of job insecurity scale $(N=306)$.

\begin{tabular}{|c|c|c|c|c|c|c|c|c|}
\hline Models & $\mathrm{x}^{2}$ & df & CFI & TLI & RMSEA* & SRMR & $\Delta \mathrm{CFI}$ & $\triangle$ RMSEA \\
\hline Model 2. Two factors - 8 items & 40.09 & 23 & 0.96 & 0.94 & 0.08 & 0.04 & -0.35 & 0.16 \\
\hline
\end{tabular}

${ }^{*} \mathrm{Cl}$, 95\% confidence interval; Note: $x^{2}$, chi-square goodness of fit statistic; df, degrees of freedom; CFI, Comparative Fit Index; TLI, Tucker Lewis Index; RMSEA, Root-Mean-Square Error of Approximation; SRMR, standardized RMR, root mean square residual.

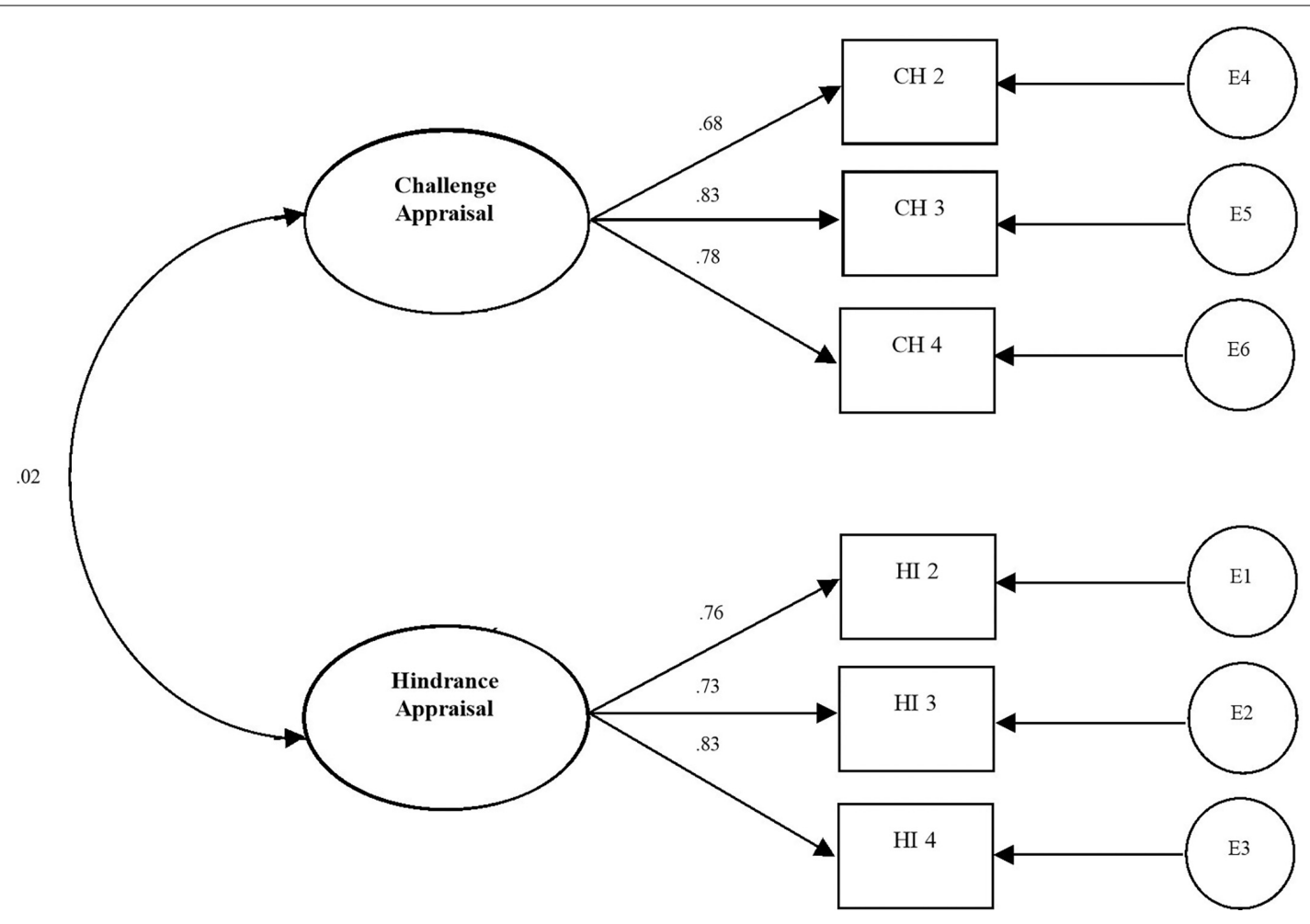

FIGURE 2 | A measurement model of the challenge-hindrance appraisal of job insecurity scale.

TABLE 2 | Means, standard deviations, and correlations among the variables $(N=306)$.

\begin{tabular}{|c|c|c|c|c|c|c|c|c|}
\hline Variable & Items & $\overline{\mathbf{x}}$ & $S D$ & 1 & 2 & 3 & 4 & 5 \\
\hline 2. Challenge appraisal & 3 & 2.74 & 0.930 & 0.058 & - & & & \\
\hline 4. Job satisfaction & 4 & 2.65 & 0.588 & $-0.218^{* * *}$ & 0.058 & $-0.131^{*}$ & - & \\
\hline 5. Emotional exhaustion & 5 & 3.17 & 1.09 & $0.241^{* * *}$ & 0.053 & $0.269^{* * *}$ & $-0.519 * * *$ & - \\
\hline
\end{tabular}

${ }^{*} p<0.05,{ }^{* *} p<0.01,{ }^{* * *} p<0.001$.

correlated with job satisfaction $(r=-0.218, p<0.001)$ and positively with emotional exhaustion $(r=0.241, p<0.001)$. In addition, the hindrance appraisal of job insecurity is negatively correlated with job satisfaction $(r=-0.131, p<0.05)$ and positively with emotional exhaustion $(r=0.269, p<0.001)$. Also for this sample, there were no significant associations between the challenge appraisals of job insecurity and well-being related outcomes.

\section{Test of the Mediation Effects of Cognitive Appraisals}

According to Figure 1, job insecurity was modeled as a predictor, and job satisfaction and emotional exhaustion as the predicted variables. Model 4 of Process program, developed by Hayes (2012), was used to test the mediation paths. Hindrance and challenge appraisals of job insecurity were added as cognitive mediators. In the first phase, the mediation effect of hindrance 
TABLE 3 | Regression results (standardized regression coefficients) predicting the outcomes $(N=306)$.

\begin{tabular}{|c|c|c|c|c|c|c|}
\hline Effect & $\beta$ & $S E$ & $t$ & $p$ & LLCI & ULCI \\
\hline $\begin{array}{l}\text { Job insecurity to } \\
\text { hindrance appraisals }\end{array}$ & 0.301 & 0.054 & 5.50 & Sig & 0.1934 & 0.4087 \\
\hline $\begin{array}{l}\text { Hindrance } \\
\text { appraisals on job } \\
\text { satisfaction }\end{array}$ & 0.053 & 0.060 & 0.883 & ns & -0.0651 & 0.1714 \\
\hline $\begin{array}{l}\text { Direct effect of job } \\
\text { insecurity on job } \\
\text { satisfaction }\end{array}$ & -0.065 & 0.060 & -1.091 & ns & -0.1839 & 0.0526 \\
\hline $\begin{array}{l}\text { Indirect effect of job } \\
\text { insecurity on job } \\
\text { satisfaction via } \\
\text { hindrance appraisals }\end{array}$ & 0.016 & 0.016 & - & ns & -0.0121 & 0.0524 \\
\hline $\begin{array}{l}\text { R-squared } \\
\text { mediation effect size }\end{array}$ & -0.001 & 0.002 & - & ns & -0.0127 & 0.0013 \\
\hline $\begin{array}{l}\text { Hindrance } \\
\text { appraisals on } \\
\text { emotional } \\
\text { exhaustion }\end{array}$ & 0.193 & 0.057 & 3.367 & Sig & 0.0803 & 0.3061 \\
\hline $\begin{array}{l}\text { Direct effect of job } \\
\text { insecurity on } \\
\text { emotional } \\
\text { exhaustion }\end{array}$ & 0.184 & 0.057 & 3.212 & Sig & 0.0714 & 0.2973 \\
\hline $\begin{array}{l}\text { Indirect effect of job } \\
\text { insecurity on } \\
\text { emotional } \\
\text { exhaustion via } \\
\text { hindrance appraisals }\end{array}$ & 0.058 & 0.022 & - & Sig & 0.0222 & 0.1097 \\
\hline $\begin{array}{l}\text { R-squared } \\
\text { mediation effect size }\end{array}$ & 0.027 & 0.011 & - & Sig & 0.0113 & 0.0588 \\
\hline \multicolumn{7}{|c|}{$R^{2}=0.09 ; F_{(1,304)}=30.29, p<0.0000$} \\
\hline
\end{tabular}

$p<0.05, p<0.01, p<0.001$.

appraisals of job insecurity between job insecurity and wellbeing related outcomes was tested. These results are displayed in Table 3. As the table shows job insecurity predicted hindrance appraisals $(\beta=0.30, p<0.001)$, as expected. Although job insecurity did not predict job satisfaction but it predicted emotional exhaustion $(\beta=0.18, p<0.001)$. Also, hindrance appraisals of job insecurity did not predict job satisfaction but they predicted emotional exhaustion $(\beta=0.19, p<0.001)$. The results of the mediation analysis showed that hindrance appraisals of job insecurity did not mediate the association between job insecurity and job satisfaction but they mediated the association between job insecurity and emotional exhaustion $(\beta=0.06, p<0.05)$.

In the second phase, the mediation effect of challenge appraisals of job insecurity between job insecurity and those same outcomes was tested. These results are displayed in Table 4. As the table shows job insecurity predicted challenge appraisals ( $\beta=0.19, p<0.001)$, as expected. Although job insecurity did not predict job satisfaction but it predicted emotional exhaustion $(\beta=0.23, p<0.0001)$. Also, challenge appraisals of job insecurity did not predict job satisfaction and emotional exhaustion. The results of the mediation analysis showed that challenge appraisals of job insecurity did not mediate the association between job insecurity and both job satisfaction and emotional exhaustion.
TABLE 4 | Regression results (standardized regression coefficients) predicting the outcomes $(N=306)$.

\begin{tabular}{|c|c|c|c|c|c|c|}
\hline Effect & $\beta$ & SE & $t$ & $p$ & LLCI & ULCI \\
\hline $\begin{array}{l}\text { Job insecurity to } \\
\text { challenge appraisals }\end{array}$ & 0.196 & 0.056 & 3.485 & Sig & 0.0853 & 0.3067 \\
\hline $\begin{array}{l}\text { Challenge appraisals } \\
\text { on job satisfaction }\end{array}$ & -0.067 & 0.058 & -1.158 & ns & -0.1125 & 0.1125 \\
\hline $\begin{array}{l}\text { Direct effect of job } \\
\text { insecurity on job } \\
\text { satisfaction }\end{array}$ & -0.036 & 0.058 & -0.622 & ns & -0.1512 & 0.0785 \\
\hline $\begin{array}{l}\text { Indirect effect of job } \\
\text { insecurity on job } \\
\text { satisfaction via } \\
\text { challenge appraisals }\end{array}$ & -0.013 & 0.012 & - & ns & -0.0439 & 0.0057 \\
\hline $\begin{array}{l}\text { R-squared } \\
\text { mediation effect size }\end{array}$ & 0.001 & 0.002 & - & ns & -0.0010 & 0.0098 \\
\hline $\begin{array}{l}\text { Challenge appraisals } \\
\text { on emotional } \\
\text { exhaustion }\end{array}$ & 0.082 & 0.056 & 1.458 & ns & 0.1457 & -0.0288 \\
\hline $\begin{array}{l}\text { Direct effect of job } \\
\text { insecurity on } \\
\text { emotional } \\
\text { exhaustion }\end{array}$ & 0.226 & 0.056 & 3.996 & Sig & 0.1149 & 0.3378 \\
\hline $\begin{array}{l}\text { Indirect effect of job } \\
\text { insecurity on } \\
\text { emotional } \\
\text { exhaustion via } \\
\text { challenge appraisals }\end{array}$ & 0.016 & 0.013 & - & ns & -0.0050 & 0.0495 \\
\hline $\begin{array}{l}\text { R-squared } \\
\text { mediation effect size }\end{array}$ & 0.009 & 0.006 & - & ns & 0.0003 & 0.0287 \\
\hline \multicolumn{7}{|c|}{$R^{2}=0.03 ; F_{(1,304)}=7.28, p<0.0006$} \\
\hline
\end{tabular}

$p<0.05, p<0.01, p<0.001$

\section{DISCUSSION}

The major goal of this research was to explore the extent to which hindrance and challenge appraisals of job insecurity mediate the association between job insecurity and well-being related outcomes. The comparison of the mediation effects of cognitive appraisals of job insecurity showed that only 1 out of 4 mediation effects were significant which was not highly strong. Consequently, sufficient evidence was not found to state that cognitive appraisals of job insecurity significantly mediate the association between job insecurity and well-being related outcomes. The only significant mediation path was the job insecurity-hindrance appraisal- emotional exhaustion, showing that a hindrance appraisal of job insecurity mediates the link between job insecurity and emotional exhaustion. This finding is explained by cognitive appraisal theory (Lazarus and Folkman, 1984). According to this theory, a hindrance appraisal of the threat (e.g., job loss) forms a negative anticipation toward how harmful the threat will be. This negative anticipation can undermine or inhibit the coping ability of employees to deal/sustain such threat as they may think that they do not have sufficient ability or means to restrain such stressor. As such, employees with this negative anticipation are expected to report more strains in terms of emotional exhaustion (Sadeghi 
Vazin et al., 2014). A supplementary explanation for this finding comes from COR theory (Hobfoll, 1989). According to this theory a threatening stressor such as job insecurity undermining the personal resources (i.e., self-efficacy: the perceived ability to overcome job uncertainty; hope: the positive anticipation to find a secure job) or conditional resources (i.e., financial security: the perceived inability to balance their life expenditures) may reduce the sustainability of employees to deal with the threat. A hindrance appraisal of this threat may consume even further the resources of the employees and result in the amplification of the job insecurity-emotional exhaustion association.

Most (3 out of 4) mediation paths were not significant. One of the non-significant effects are related to the mediating role of hindrance appraisals of job insecurity and two to the mediating role of challenge appraisals of job insecurity. The non-significant effects might be due to the following reasons. Hindrance appraisals did not mediate the association between job insecurity and job satisfaction. This might be related to the employment situation of the Iranian participants. As demographic information shows, 79.7\% of the participants had a temporary contract. This high rate of temporary contracts in our sample may explain the lack of mediation in the aforementioned association. Employees with temporary contracts are less likely to perceive job insecurity as a breach of their psychological contract with the employer, resulting in less negative reactions (De Cuyper and De Witte, 2006). One reason could be that temporary employees might expect to receive less job security compared to permanent employees (De Cuyper et al., 2010). It means that the lack of job security, as a breach, for the temporary employees might not be as threatening as it might be for the permanent employees. As such, employees are less likely to appraise the breach of psychological contract (e.g., job insecurity) as a hindrance, resulting in no mediation effect. Another reason for not finding a mediation role for hindrance appraisals of job insecurity between job insecurity and job satisfaction might be related to the type of job insecurity was measured. In this respect, researchers claim that quantitative job insecurity has a stronger association with health-related outcomes (e.g., emotional exhaustion) than qualitative job insecurity, whereas qualitative job insecurity has a stronger negative association with job attitudes (e.g., job satisfaction) than quantitative job insecurity (Hellgren et al., 1999). As such, a hindrance appraisal of quantitative job insecurity might have a more detrimental impact in the job insecurity-emotional exhaustion rather than in the job insecurity-job satisfaction association, as found.

No confirmation was found for the mediating role of challenge appraisals of job insecurity in the relationship between job insecurity and outcomes. This shows that what scientists may assume about the protective role of the challenge appraisals in the job insecurity-wellbeing association is not a correct assumption. Since most mediation effects were non-significant, we may conclude that cognitive appraisals of job insecurity do not play a determinant mediating role in the association between job insecurity and outcomes, at least not in the studied sample and country. Our findings suggest that one should distinguish emotional mediators (e.g., social support, affects, and optimism) from cognitive mediators (hindrance vs. challenge appraisals) in the job insecurity-well-being association. According to prior studies, emotional factors may be more likely (e.g., Xanthopoulou et al., 2007) to influence the job insecuritywell-being association than the cognitive factors tested in this study.

The impact of job insecurity on outcomes was replicated in Iran. The results showed that job insecurity is associated with job satisfaction and emotional exhaustion. This replication suggests that the detrimental impact of job insecurity on outcomes is not context specific. The results also showed that hindrance appraisals of job insecurity predict emotional exhaustion. In contrast, challenge appraisals of job insecurity were unrelated to both outcomes. We may thus conclude that hindrance appraisals of job insecurity are more likely to provoke negative outcomes than challenge appraisals. This is consistent with the propositions of cognitive appraisal theory (Lazarus and Folkman, 1984). Accordingly, a perceived hindrance (i.e., job insecurity) is assumed to stimulate a hindrance appraisal. A hindrance appraisal of a stressor is anticipated to result in more various negative outcomes because such appraisals intensify negative feelings of concern and uncertainty. As such, employees may be driven to overestimate the adverse aspects of a threat compared to possible positive aspects. These negative feelings may reduce the personal resources of individuals (e.g., self-efficacy, hope) and produce strains. Challenge appraisals were not associated with the outcomes. We may conclude that this might be because of the fully negative nature of job insecurity in the perceptions of employees. The perception of job insecurity as a hindrance may make greater imbalances in the loss-gain ratio of resources of an individual. In contrast, the perception of job insecurity as a challenge may make fewer imbalances in the same ratio of an individual. The greater perceived imbalance may be more likely to influence the outcomes than the fewer perceived imbalance.

\section{Suggestions for Future Research}

An interesting question for future studies is: what makes an employee appraise job insecurity as a hindrance or as a challenge? Lazarus and Folkman (1984) argued that the cognitive evaluation of a stressor affects not only how stressed you feel, but also what coping strategies you choose, adjust or deal, to overcome a stressor. In doing so, various factors may influence the cognitive evaluation of job insecurity. One might be related to the type of stressor. Stressors that are perceived to have the potential for rewards (e.g., praise and recognition), growth (e.g., learning new things), and mastery (e.g., reaching for a better position) are more likely to be appraised as a challenge; whereas those that are perceived to threaten one's well-being by frustrating goal attainment and personal development are more likely to be appraised as a hindrance (Lazarus and Folkman, 1984; Skinner and Brewer, 2002; Storch et al., 2007; Webster et al., 2011). For example, job insecurity as a work-related concern has the potential to involve employees in professional development and financial rewards by seeking for an alternative secure 
job (a challenge appraisal of job insecurity), but also has the potential to demotivate employees to seek for new job opportunities because of the unpredictability of job demands and role complexity of a new job (a hindrance appraisal of job insecurity). The concentration of an employee on the negative (i.e., overestimation of negative impact) or positive (i.e., underestimation of negative impacts) sides of a threat may lead to a hindrance or a challenge appraisal of that threat, respectively. A second factor that may influence the cognitive evaluation of individuals of a threat relates to the level of personal resources. Based on cognitive appraisal theory (Lazarus and Folkman, 1984) and conservation of resources theory (Hobfoll, 1989), individuals who are low in personal resources might be more vulnerable compared to those who are high (Weiss et al., 1999). According to these theories individuals with a lower level of personal resources are more likely to appraise job insecurity as a hindrance rather than a challenge. Future studies may want to examine this hypothesis. A third factor might be associated with the job opportunities or different social security system of a given country. These are so-called societal resources (Senterfitt et al., 2013). Employees of countries with a strong social security system and high job opportunities are probably less likely to appraise job insecurity as a hindrance. They are aware that if they lose their job, they can still be financially supported by their government until they find a new job. Note that this study did not include the possible effects of the societal resources. Future studies may want to test the effect of these and similar societal resources in samples comprising a larger set of countries.

\section{Strengths and Limitations}

The present study contributes to the job insecurity literature in several ways. First, it examines whether the job insecuritywell-being relationship depends on cognitive appraisals of employees of job insecurity. As such, some evidence was found for hindrance appraisals of job insecurity as mediator of the job insecurity-emotional exhaustion association. This finding strengthens the propositions of cognitive appraisal theory. No evidence, however, was found for challenge appraisals of job insecurity as mediator of the job insecurity-well-being relationship. Second, despite the differences in the culture, economic systems, and welfare regimes of Iran, this study replicates the negative associations of job insecurity with two core well-being outcomes, job satisfaction, and emotional exhaustion. Besides, organizational managers may use these findings to design supportive and training programs that help employees to reduce their detrimental appraisal of job insecurity. For example, they can provide employees with enough information of the organizational resources and supports available (Huang et al., 2014), talking to them about the negative consequences of their hindrance appraisals and the way they can turn them into less detrimental appraisals using a clear, realistic, and pragmatic communication program, along with the participation of employees [suggested by Vander Elst et al. (2010a, 2014a)], and talking about societal resources available (e.g., social support programs, job loss insurance, bank loans) where they work.

There are also several limitations related to this research that may have affected our conclusions. First, the findings were established based on a cross-sectional research design, which does not allow to study of mediating effects over time. Job insecurity is a phenomenon which is influenced by social and economic shocks (e.g., Setayesh and Mackey, 2016). Studying mediating effects over time may show differences in how cognitive mediators influence the association between job insecurity and wellbeing (Vander Elst et al., 2014a; Piccoli and De Witte, 2015). Future research may apply a longitudinal research design to test the short and long term impacts of job insecurity on these outcomes and to test the influence of both appraisals in the job insecurity-well-being link over time. A second possible limitation concerns the characteristics of the sample: women and whitecollar workers were over-represented in comparison to men and blue-collar workers. This selection of workers might limit the generalizability of our findings (e.g., De Witte and Näswall, 2003).

\section{CONCLUSION}

This research explored that cognitive appraisals of job insecurity hardly play a mediating role in the job insecurity-well-being association. However, when employees appraise job insecurity as a hindrance stressor, job insecurity is more likely to be detrimental and to provoke negative responses. As such, employees hindered by job insecurity are more likely to be emotionally exhausted by perceived job insecurity. Challenge appraisals of job insecurity did not show to have the expected protective role. The replication of the results in Iran, along with same results in other countries, suggested that the detrimental impact of job insecurity on key aspects of wellbeing (e.g., job satisfaction and emotional exhaustion) is not country-specific.

\section{ETHICS STATEMENT}

This study was approved in the Ethical committee of Shahid Beheshti Medical University of Tehran, Iran.

\section{AUTHOR CONTRIBUTIONS}

MC conducted the research, analyzed the data, and wrote the manuscript.

\section{FUNDING}

The paper was prepared within the framework of the Academic Fund Program at the National Research University Higher School of Economics HSE in 2018 Grant No. 18-05-0001 and by the Russian Academic Excellence Project “5-100.” 


\section{REFERENCES}

Arbuckle, J. L. (2005). Amos 6.0 User's Guide. Spring House, PA: AMOS Development Corporation.

Barsky, A., Kaplan, S. A., and Beal, D. J. (2011). Just feelings? the role of affect in the formation of organizational fairness judgments. J. Manag. 37, 248-279. doi: $10.1177 / 0149206310376325$

Bollen, K. A., and Long, J. S. (eds). (1993). Testing Structural Equation Models. Newbury Park, CA: Sage Publications. doi: 10.1177/0149206310376325

Browne, M. W., and Cudeck, R. (1993). “Alternative ways of assessing model fit," in Testing Structural Equation Models, eds K. A. Bollen and J. S. Long (Thousand Oaks, CA: SAGE Publications), 136-162.

Byrne, B. M. (2001). Structural Equation Modeling with Amos Basic Concepts Application and Programming. London: Lawrence Erlbaum.

Cavanaugh, M. A., Boswell, W. R., Roehling, M. V., and Boudreau, J. W. (2000). An empirical examination of self-reported work stress among U.S. managers. J. Appl. Psychol. 85, 65-74. doi: 10.1037//0021-9010.85.1.65

Charkhabi, M., Pasini, M., and De Witte, H. (2015). "Job insecurity: hindrance or challenge? a pilot study on a job insecurity appraisal scale by the cognitive interview method," in Poster at The 17th European Congress of Work and Organizational Psychology, Oslo.

Cheng, G. H., and Chan, D. K. (2008). Who suffers more from job insecurity? a meta-analytic review. Appl. Psychol. 57, 272-303. doi: 10.1111/j.1464-0597. 2007.00312.x

De Cuyper, N., and De Witte, H. (2006). The impact of job insecurity and contract type on attitudes, well-being and behavioral reports: a psychological contract perspective. J. Occup. Organ. Psychol. 79, 395-409. doi: 10.1348/ $096317905 \times 53660$

De Cuyper, N., De Witte, H., Kinnunen, U., and Nätti, J. (2010). The Relationship between job insecurity and employability and well-being among finnish temporary and permanent employees. Int. Stud. Manag. Organ. 40, 57-73. doi: 10.2753/imo0020-8825400104

De Witte, H. (2000). “Arbeidsethos en jobonzekerheid: Meting engevolgen voor welzijn, tevredenheid en inzet op het werk [Work ethic and job insecurity: assessment and consequences for wellbeing, satisfaction and performance at work]," in Van Groep Naar Gemeenschap [From Group to Community], eds R. Bouwen, K. De Witte, H. De Witte, and T. Taillieu (Leuven: Garant), 325-350.

De Witte, H. (2005). Job insecurity: review of the international literature on definitions, prevalence, antecedents and consequences. SA J. Ind. Psychol. 31:a200. doi: 10.4102/sajip.v31i4.200

De Witte, H., and Näswall, K. (2003). 'Objective' vs 'subjective' job insecurity: consequences of temporary work for job satisfaction and organizational commitment in Four European Countries. Econ. Ind. Democracy 24, 149-188. doi: $10.1177 / 0143831 \times 03024002002$

De Witte, H., Pienaar, J., and De Cuyper, N. (2016). Review of 30 Years of longitudinal studies on the association between job insecurity and health and well-being: is there causal evidence? Aust. Psychol. 51, 18-31. doi: 10.1111/ap. 12176

De Witte, H., Vander Elst, T., and De Cuyper, N. (2015). "Job insecurity, health, and well-being," in Sustainable Working Lives: Managing Work Transitions and Health Throughout the Life Course, eds J. Vuori, R. Blonk, and R. H. Price (New York, NY: Springer), 109-128. doi: 10.1007/978-94-017-9798-6

Furåker, B., and Berglund, T. (2013). Job insecurity and organizational commitment. Rev. Int. Organ. 13, 163-186.

Glavin, P., and Schieman, S. (2014). Control in the face of uncertainty: is job insecurity a challenge to the mental health benefits of control beliefs? Soc. Psychol. Q. 77, 319-343. doi: 10.1177/0190272514546698

Hamad, R., Modrek, S., and Cullen, M. R. (2015). The Effects of job insecurity on health care utilization: findings from a panel of U.S. workers. Health Serv. Res. 51, 1052-1073. doi: 10.1111/1475-6773.12393

Hayes, A. F. (2012). Process: A Versatile Computational Tool for Observed Variable Mediation, Moderation, and Conditional Process Modeling [White Paper]. Available at: http://www.afhayes.com/public/process2012.pdf

Hellgren, J., Sverke, M., and Isaksson, K. (1999). A two-dimensional approach to job insecurity: consequences for employee attitudes and well-being. Eur. J. Work Organ. Psychol. 8, 179-195. doi: 10.1080/13594329939 8311
Hobfoll, S. E. (1989). Conservation of resources: a new attempt at conceptualizing stress. Am. Psychol. 44, 513-524. doi: 10.1037//0003-066x.44.3.513

Hoyle, R. H. (1995). Structural Equation Modelling: Concepts, Issues, and Applications. Thousand Oaks, CA: Sage Publications.

Hu, L., and Bentler, P. M. (1999). Cut off criteria for fit indexes in covariance structure analysis: conventional criteria versus new alternatives. Struct. Equ. Modeling 6, 1-55. doi: 10.1080/10705519909540118

Huang, G., Zhao, H. H., Niu, X., Ashford, S. J., and Lee, C. (2014). "Reducing job insecurity and increasing performance ratings: does impression management matter?": correction to Huang et al. (2013). J. Appl. Psychol. 99, 86-86. doi: 10.1037/a0035129

Jiang, L., and Probst, T. M. (2015). The relationship between safety-production conflict and employee safety outcomes: testing the impact of multiple organizational climates. Work Stress 29, 171-189. doi: 10.1080/02678373.2015. 1032384

Kline, R. B. (1998). Principles and Practice of Structural Equation Modeling. New York, NY: Guilford Press.

Lazarus, R. S., and Folkman, S. (1984). Stress, Appraisal and, Coping. New York NY: Springer.

Lim, D., Baek, K., Chung, I., and Lee, M. (2014). Factors related to sleep disorders among male firefighters. Ann. Occup. Environ. Med. 26:11. doi: 10.1186/20524374-26-11

Marsh, H. W. (2001). Distinguishing between good (useful) and bad workloads on students' evaluations of teaching. Am. Educ. Res. J. 38, 183-212. doi: 10.3102/ 00028312038001183

Maslach, C., Jackson, S. E., and Leiter, M. P. (1996). MBI: The Maslach Burnout Inventory: Manual. Palo Alto, CA: Consulting Psychologists Press.

Maslach, C., and Leiter, M. P. (2008). Early predictors of job burnout and engagement. J. Appl. Psychol. 93, 498-512. doi: 10.1037/0021-9010.93. 3.498

McDonough, P. (2000). Job insecurity and health. Int. J. Health Serv. 30, 453-476. doi: $10.2190 / \mathrm{bpfg}$-x3me-lhta-6rpv

Öztürk, E. B., Karagonlar, G., and Emirza, S. (2017). Relationship between job insecurity and emotional exhaustion: moderating effects of prevention focus and affective organizational commitment. Int. J. Stress Manag. 24, 247-269. doi: $10.1037 /$ str0000037

Peeters, J. (2014). Jobonzekerheid als Werkeis: Hindernis of Uitdaging? (Job insecurity as work demand: hindrance or challenge?). Ph.D. thesis, Faculty of Psychology and Educational Sciences, Leuven.

Piccoli, B., and De Witte, H. (2015). Job insecurity and emotional exhaustion: Testing psychological contract breach versus distributive injustice as indicators of lack of reciprocity. Work Stress 29, 246-263. doi: 10.1080/02678373.2015. 1075624

Price, J. L. (1997). Handbook of Organizational Measurement. Bradford: MCB University Press.

Probst, T. M. (2008). "Job Insecurity," in The SAGE Handbook of Organizational Behavior, eds J. Barling and C. L. Cooper (London: Sage), 178-195.

Probst, T. M., Barbaranelli, C., and Petitta, L. (2013). The relationship between job insecurity and accident under-reporting: a test in two countries. Work Stress 27, 383-402. doi: 10.1080/02678373.2013.850756

Sadeghi Vazin, A., Shokri, O., PourShahriar, H., and Bagherian, F. (2014). Occupational stress, coping strategies and strains: a model of gender invariance. J. Iran. Psychol. 10, 393-408.

Schaufeli, W. B. (2016). Job insecurity research is still alive and kicking twenty years later: a commentary. Aust. Psychol. 51, 32-35. doi: 10.1111/ap.12201

Senterfitt, J. W., Long, A., Shih, M., and Teutsch, S. M. (2013). How Social and Economic Factors Affect Health: Social Determinants of Health. Available at: http://www.publichealth.lacounty.gov/epi/

Setayesh, S., and Mackey, T. K. (2016). Addressing the impact of economic sanctions on Iranian drug shortages in the joint comprehensive plan of action: promoting access to medicines and health diplomacy. Global. Health 12:31. doi: 10.1186/s12992-016-0168-6

Skinner, N., and Brewer, N. (2002). The dynamics of threat and challenge appraisals prior to stressful achievement events. J. Personal. Soc. Psychol. 83, 678-692. doi: 10.1037/0022-3514.83.3.678

Storch, M., Gaab, J., Küttel, Y., Stüssi, A., and Fend, H. (2007). Psychoneuroendocrine effects of resource-activating stress management training. Health Psychol. 26, 456-463. doi: 10.1037/0278-6133.26.4.456 
Sverke, M., Hellgren, J., and Näswall, K. (2002). No security: a meta-analysis and review of job insecurity and its consequences. J. Occup. Health Psychol. 7, 242-264. doi: 10.1037/1076-8998.7.3.242

Vander Elst, T., Baillien, E., De Cuyper, N., and De Witte, H. (2010a). The role of organizational communication and participation in reducing job insecurity and its negative association with work-related well-being. Econ. Ind. Democracy 31, 249-264. doi: 10.1177/0143831x09358372

Vander Elst, T., De Cuyper, N., and De Witte, H. (2010b). The role of perceived control in the relationship between job insecurity and psychosocial outcomes: moderator or mediator? Stress Health 27, e215-e227. doi: 10.1002/smi. 1371

Vander Elst, T., Richter, A., Sverke, M., Näswall, K., De Cuyper, N., and De Witte, H. (2014a). Threat of losing valued job features: the role of perceived control in mediating the effect of qualitative job insecurity on job strain and psychological withdrawal. Work Stress 28, 143-164. doi: 10.1080/02678373.2014.89 9651

Vander Elst, T., Van den Broeck, A., De Cuyper, N., and De Witte, H. (2014b). On the reciprocal relationship between job insecurity and employee wellbeing: mediation by perceived control? J. Occup. Organ. Psychol. 87, 671-693. doi: 10.1111/joop.12068

Wang, H., Lu, C., and Siu, O. (2015). Job insecurity and job performance: the moderating role of organizational justice and the mediating role of work engagement. J. Appl. Psychol. 100, 1249-1258. doi: 10.1037/a003 8330
Webster, J. R., Beehr, T. A., and Love, K. (2011). Extending the challenge-hindrance model of occupational stress: the role of appraisal. J. Vocat. Behav. 79, 505-516. doi: 10.1016/j.jvb.2011.02.001

Weiss, H. M., Suckow, K., and Cropanzano, R. (1999). Effects of justice conditions on discrete emotions. J. Appl. Psychol. 84, 786-794. doi: 10.1037/0021-9010.84. 5.786

Weston, R., and Gore, P. A. (2006). A brief guide to structural equation modeling. Couns. Psychol. 34, 719-751. doi: 10.1177/0011000006286345

Xanthopoulou, D., Bakker, A. B., Demerouti, E., and Schaufeli, W. B. (2007). The role of personal resources in the job demands-resources model. Int. J. Stress Manag. 14, 121-141. doi: 10.1037/1072-5245.14.2.1

Zheng, X., Diaz, I., Tang, N., and Tang, K. (2014). Job insecurity and job satisfaction. Career Dev. Int. 19, 426-446. doi: 10.1108/cdi-10-2013-0121

Conflict of Interest Statement: The author declares that the research was conducted in the absence of any commercial or financial relationships that could be construed as a potential conflict of interest.

Copyright ( $(2019$ Charkhabi. This is an open-access article distributed under the terms of the Creative Commons Attribution License (CC BY). The use, distribution or reproduction in other forums is permitted, provided the original author(s) and the copyright owner(s) are credited and that the original publication in this journal is cited, in accordance with accepted academic practice. No use, distribution or reproduction is permitted which does not comply with these terms. 